\title{
Parasitic Infections in an Animal Shelter
}

\author{
V. SVOBODOVÁ \\ Department of Parasitology, Faculty of Veterinary Medicine, \\ University of Veterinary and Pharmaceutical Sciences Brno, Czech Republic
}

Received February 18, 2003

Accepted September 22, 2003

\begin{abstract}
Svobodová V .: Parasitic Infections in an Animal Shelter. Acta Vet. Brno 2003, 72: 415-420.

The aim of the present study was to monitor the circulation of parasitic infections and the general parasitological situation in the environment of a shelter for dogs and cats during routine operation. The study was performed during a 3-month period in a shelter with capacity of 30 animals. We regularly examined the haircoat of sheltered animals for the occurrence of fleas. At the same time samples of dog faeces were collected for parasitological examination. The animals were treated with selamectin (Stronghold) for protection against parasites. The preparation reduced the flea population and it also proved highly effective against ascarids in dogs and cats. We detected an infection with other parasites (Dipylidium caninum, Taenia sp., Trichuris vulpis, Giardia lamblia) and treated the positive animals accordingly with $5 \mathrm{mg} \mathrm{kg}^{-1}$ of praziquantel and $50 \mathrm{mg} \mathrm{kg}^{-1}$ of fenbendazole during three days (Caniquantel Plus). The study indicated that protection against parasites in shelters for animals needs more complex measures than in households with individually kept dogs and cats.
\end{abstract}

Dog, cat, parasites, fleas, control

The occurrence of fleas and other parasites is a continuous challenge for animal shelters. In order to manage the situation it is necessary to administer effective drugs and to maintain a high level of hygiene. Due to the facts that appropriate measures require much time and that groups of animals in shelters are constantly changing because of continuous migration of the animals, parasitic infections are considered to be an inherent factor of the environment of animal shelters.

Flea infestation does not mean only discomfort for the animals but it may also cause anaemia especilly in juvenile and weak individuals. Together with the stress often experienced by the animal before sheltering, the condition may lead to generalized distress. From the infested individuals fleas may quickly spread to other animals in the shelter. Dogs and cats sheltered for a long period may also manifest allergic reactions to flea bites. This results in deteriorated hair quality. Poor aesthetic appearance of an affected animal reduces its chances for adoption. Moreover, fleas are also the most frequent and most important intermediate hosts of the tapeworm (Dipylidium caninum). In the environment with higher concentration of animals the spread of the infection with this tapeworm can be very fast. Cat flea (Ctenocephalides felis felis) is the currently most widespread species. It can be found in dogs, cats and frequently also in humans. The fleas disturb the staff of the shelters and may discourage potential new owners from adopting a sheltered animal.

The occurrence of internal parasitic infections is also very frequent due to continuous migration of the animals. More significant clinical manifestations may also occur as a result of the preceding history. Contamination of the environment with eggs and cysts of parasites facilitates re-infection of the animals and poses a risk for humans since zoonotic parasites are commonly found in animal shelters. Infected dogs and cats are involved in further spread of parasites and thus endanger their new owners.

Address for correspondence:

Prof. MVDr. Vlasta Svobodová, CSc.

Department of Parasitology, Faculty of Veterinary Medicine

University of Veterinary and Pharmaceutical Sciences Brno

Palackého 1-3,612 42 Brno, Czech Republic hone: +420541562 265

Fax: +420549248841

http://www.vfu.cz/acta-vet/actavet.htm 
The aim of the present study was to monitor the circulation of parasitic infections and the general parasitological situation in the environment of a shelter for dogs during routine operation.

\section{Materials and Methods}

The study was carried out in a shelter for dogs where 20-25 dogs and occasionally some cats are housed. The success rate in finding new owners for the animals is relatively high, but still some animals have been spending several months in the facility. The dogs are housed in pens with concrete floor and wooden kennels either individually or in pairs. Last administration of antiparasitics was carried out 4 months prior to the beginning of our study.

The method used in the present study was a modification of the procedure by Shanks et al. (2000) focused on efficacy of selamectin against fleas and roundworms (ascarids). The animals currently present in the shelter were examined for flea infestation and parasitological examination of faeces was carried out on days $0,14,29$, $44,59,74$ and 90 of the study. The examination included inspection of the hair for fleas or their faeces. The intensity of flea infestation was differentiated and recorded as follows:

+ small solitary affected site with some flea faeces or 1-2 fleas,

++ large affected site with flea faeces or 3-5 fleas,

+++ affected sites with flea faeces and more than 6 fleas found all over the body.

The differentiation and confirmation of the finding of flea faeces was carried out by combing out and wetting the detritus from hair. On a sheet of filter paper, dissolving particles of flea faeces form brown-red spots which mark the difference from ordinary dirt from the hair. At the same time samples of dog faeces were collected for parasitological examination. The parasites excreted from the body were identified by macroscopic (ascarids) or microscopic inspection (excreted tapeworm segments) based on typical morphological features. Then the samples of faeces were processed and microscopically examined. Antiparasitic product selamectin (Stronghold) was administered on the skin of withers in all dogs and cats housed in the shelter. The dose depended on the size of the animal. The product was administered on day 0 of the study. Every 14 days thereafter the hair of the animals was inspected to detect possible flea infestation and parasitological examination of faeces was carried out. The animals kept in the shelter for a long time were repeatedly treated with selamectin at monthly intervals for a total period of 3 months. Prior to housing in a pen each new animal was examined for flea infestation, and treated with selamectin. The information about the animal was recorded, and in case of its prolonged stay in the shelter the following treatments could be scheduled at a monthly intervals. Examinations of hair and faeces in newly admitted animals were scheduled for the next appropriate date of observation. Therapy with $5 \mathrm{mg} \cdot \mathrm{kg}^{-1} \mathrm{of}$ praziquantel and $50 \mathrm{mg} \cdot \mathrm{kg}^{-1}$ of fenbendazole for three days (Caniquantel Plus) was carried out in animals with positive faecal findings on day 44 of the study. The therapy against protozoan flagellates (Giardia lamblia) was repeated after the next faecal examination. The therapy against whipworms (Trichuris vulpis) in dogs was carried out after each finding of these parasites. Newborn puppies were treated against ascarids with the antiparasitic paste Banminth (pyrantel) at the age of two and four weeks. Selamectin was administered to 6-week-old puppies before they were given to their new owners.

\section{Results}

A total of 19 animals (14 dogs and 5 cats) were kept in the shelter at the beginning of the monitoring period. During this period, 16 more animals were brought to the shelter (12 dogs and 4 cats). New owners adopted altogether 16 animals ( 9 dogs and 7 cats). One bitch gave birth to 4 puppies three days after admission to the shelter. Later on, one of the puppies died.

Day 0 - First administration of selamectin

Number of animals in the shelter: 19 (14 dogs and 5 cats).

Examination of flea infestation

Fleas were found in 2 cats (2/5) (+) and $10 \mathrm{dogs}(10 / 14)$, with the classification as follows:

+ in 4 dogs of $10,++$ in $4 / 10,+++$ in $2 / 10$.

Examination of faeces

Cats: Toxocara cati $3 \times(3 / 5)$, Dipylidium caninum $2 \times(2 / 5)$.

Dogs: Toxocara canis $2 \times(2 / 14)$, Dipylidium caninum $1 \times(1 / 14)$. 
Day 14

Number of animals in the shelter: 21 (16 dogs and 5 cats).

Examination of flea infestation

Fleas were confirmed in 5 dogs $(5 / 16)$, with the classification as follows: + in 4 dogs of 5 , ++ in $1 / 5$. Out of the original group of dogs fleas were found in 3 animals (out of 5), in 2 dogs the intensity of infestation was reduced from +++ to $+(2 / 3)$. In $1 \mathrm{dog}(1 / 3)$ mild intensity of infestation (+) persisted from the previous period.

Examination of faeces

Cats: Dipylidium caninum $2 \times(2 / 5)$.

Dogs: Toxocara canis $1 \times(1 / 16)$, Dipylidium caninum $1 \times(1 / 16)$.

Day 29 - Second administration of selamectin

Number of animals in the shelter: 23 (19 dogs and 4 cats).

Examination of flea infestation

The faeces of fleas were found in $2 \operatorname{dogs}(2 / 19)$, intensity: +.

Examination of faeces

Cats: negative

Dogs: Trichuris vulpis $2 \times(2 / 19)$, Giardia lamblia $7 \times(7 / 19)$.

Day 44

Number of animals in the shelter: 25 ( 22 dogs and 3 cats).

Examination of flea infestation

Fleas and flea faeces were found in one dog $(1 / 22)$, intensity ++ .

Examination of faeces

Cats: Dipylidium caninum $2 \times(2 / 3)$, Isospora rivolta $1 \times(1 / 3)$, Giardia lamblia $1 \times(1 / 3)$. Dogs: Dipylidium caninum $1 \times(1 / 22)$, Taenia sp. $1 \times(1 / 22)$, Trichuris vulpis $2 \times(2 / 22)$, Giardia lamblia $4 \times(4 / 22)$.

Day 59 - Third administration of selamectin

Number of animals in the shelter: 26 (24 dogs and 2 cats).

Examination of flea infestation

Fleas and flea faeces were not found in any animals.

Examination of faeces

Cats: negative.

Dogs: Trichuris vulpis $1 \times(1 / 24)$, Isospora ohioensis $1 \times(1 / 24)$, Giardia lamblia $6 \times(6 / 24)$.

Day 74

Number of animals in the shelter: 24 (22 dogs and 2 cats).

Examination of flea infestation

Not found.

Examination of faeces

Cats: negative.

Dogs: Toxocara canis $3 \times(3 / 22$ - found in faeces of the puppies born in the shelter after pyrantel administration, Trichuris vulpis $1 \times(1 / 22)$, Giardia lamblia $8 \times(8 / 22)$.

Day 90

Number of animals in the shelter: 25 (23 dogs and 2 cats).

Examination of flea infestation

Not found.

Examination of faeces 
Cats: negative.

Dogs: Trichuris vulpis $2 \times(2 / 23)$, Toxocara canis $2 \times(2 / 23$ - found in two of the three puppies mentioned above, Giardia lamblia $9 \times(9 / 23)$ - including the 3 puppies born in the shelter (3/9).

\section{Discussion}

Animal shelters provide favourable conditions for the spread of parasitic infections. Continuous migration of animals requires a strict observation of effective antiparasitic measures targeted against most frequently occurring external and internal parasites.

Selamectin with its broad-spectrum antiparasitic effect was found to be the drug of choice for animal shelters. In accordance with the action against fleas described by McTier et al. (2000a) we demonstrated a remarkable reduction in the flea population. From day 59 of the study until the final day 90, no more fleas were found. Thus pruritus was also reduced and the affected animals became calmer. Selamectin was also effective against ascarids in dogs and cats as reported by Mc Tier et al. (2000bc). Ascarids were found in cats during the entry examination in 3 of 5 animals but after selamectin administration no more ascarids were found even after repeated examination. The study of prevalence of parasitic infections in dogs and cats in the Czech Republic (Svobodová et al. 1995) showed that ascarids (Toxocara cati) occur in the small intestine of $18 \%$ of cats of all age categories. The probability of occurrence is higher in neglected animals that come to the shelters and therefore a regular care is of great importance. Despite the fact that (in particular) especially in young dogs under one year of age are infected with adult stages of ascarids, most animals coming to the shelters are sources of infection. In the Czech Republic, ascarids (Toxocara canis) were confirmed in $17 \%$ of dogs (Svobodová et al. 1995). However, there are considerable variations between different age groups, which was also confirmed by positive findings in puppies born in the shelter, although their mother tested negative. Administration of selamectin reliably killed the ascarids and this is important not only for the health of dogs and cats, but also for human health. The infection in humans is manifested as larval toxocarosis. Prevalence of specific antibodies in inhabitants of the Czech Republic was $25 \%$ (Uhlíková and Hübner 1999).

The scope of parasitic infections affecting dogs and cats in shelters includes some less known species that are, however, spreading very quickly and that unfortunately cannot be controlled with a broad-spectrum product. Giardia lamblia has a particular importance among protozoan agents. It was diagnosed in $5.5 \%$ of all animals in the dog population in the Czech Republic. The infection is found especially in puppies. S v obodová et al. (1995) confirmed giardiasis in $25 \%$ of puppies. The infection is manifested by diarrhoea which affects in particular young animals and weak individuals. Asymptomatic form is predominant in adult animals. First diagnosis of giardiosis in our study was made on day 29 in dogs. Subsequently the cats became affected, too. Despite repeated therapy with fenbendazole (Zajac et al. 1998), in our study cysts were shed by ever more animals until the final day 90 . We have not been able to eliminate giardiasis from the shelter due to favourable conditions of spread of the parasite. Nevertheless, the course of the infection was asymptomatic. Therefore we terminated the therapy. Based on these observations we do not recommend general use of this therapy in animal shelters. On the other hand, giardiosis in puppies poses serious health problems. Due to high probability of occurrence of giardia cysts in the environment of animal shelters the measures against this parasitosis should be focused on young animals and/or considerably weak animals which should be effectively protected by therapy and/or vaccination. Although humans can also be infected by Giardia lamblia, according to the current knowledge it is not assumed that giardia originating from dogs and cats would have any important share in human giardiosis (Monis et al. 1998). Therapy of 
giardiosis can be, however, always recommended to the new owner upon adopting a dog or a cat from shelter, because the probability of the infection is high and its confirmation by finding of cysts in faeces may be unreliable with a single examination.

In our study, it was not necessary to treat isosporosis, which occurred for a short period in dogs and cats. The reason was that the positive animals were already older than six months. The coccidia found are pathogenic in particular for young animals under 12 to 16 weeks of age (Dubey 1993).

The confirmation of the occurrence of whipworms (Trichuris vulpis) was in our opinion very dangerous for the health status of the dogs. Whipworms can cause serious inflammation of the large intestine manifested by haemorrhagic diarrhoea and loss of weight in dogs of all age groups. The eggs of these parasites are shed in faeces, they are very resistant and can survive in external environment for several years. Therefore, even mild infections will gradually result in a considerable contamination of the environment. Under such conditions whipworm infections continue to pose constant problems. The prevalence in the shelter was significantly above the mean level of $1.1 \%$ detected in the population of dogs in the Czech Republic (Svobodová et al. 1995). This was the reason why in case of a positive finding we treated the affected dogs even if the occurrence of eggs in faeces was sporadic and no clinical symptoms of the disease were present. In case of confirmed infection with whipworms we recommend to start immediately with targeted therapy consisting of the administration of benzimidazole products for the period of several days (Kassai 1999). Fenbendazole was used in our study.

Since the fleas as intermediate hosts of tapeworm (Dipylidium caninum) were eliminated, after the therapy of dipylidiosis in three cats and one dog with the infection confirmed at the beginning of the study no new infections were found. The infection with tapeworms of the genus Taenia was also successfully managed by the therapy. Infection with Taenia tapeworms can be avoided if the animals cannot hunt rodents and if commercial animal feed is used.

Parasitological situation in the shelter is very complicated, and it is usually impossible to manage by the administration of a single product despite its broad-spectrum effects. On day 44 of our study, having taken into account the results of parasitological examination of faeces, we decided to extend the treatment by adding another antiparasitic drug. Repeated occurrence of tapeworms, giardia and whipworms was managed by administration of a product, the composition of which (praziquantel and fenbendazole) matched with the requirements for the therapy against the parasites found. The drug was administered for a period of three days in order to ensure simultaneous effect against giardia, whipworms and tapeworms and not to increase stress of the affected animals by frequent administration of tablets.

Our study of parasitic infections in the shelters for dogs and cats confirmed that monitoring of parasitic infections in the shelters for dogs and cats requires a more radical approach than monitoring the same parameters for owners of individual animals or groups of breeding animals. The situation is complicated in particular by continuous migration of the animals and by the fact that the care for animals is affected due to stress and unfavourable conditions of life. Due to these facts the animals are more susceptible to infections and their pathogenic effects. Parasitological management has to contain preventive measures represented by general administration of a broad-spectrum preparation that can affect the most frequently found parasites. Selamectin eliminates the populations of fleas and is also effective against ascarids in dogs and cats even in an epidemiologically challenging environment of shelters for dogs and cats. Regular administration of selamectin will considerably improve the quality of life of the animals kept in shelters and will also increase their chances for adoption. The examination of faeces of sheltered dogs and cats should be carried out at least twice 
a year, and in addition to this also individually upon admission to the shelter and in cases of diarrhoea lasting for more than 2 days. This will be an inevitable factor to eliminate contamination of the environment and for the control of spread of parasitic diseases. Additional measures and therapy should be taken into consideration in the animals with positive parasitological findings. The usual single administration of a randomly selected antiparasitic drug may be pointless for instance just in the case of whipworms. In juvenile animals and weak individuals it is necessary to focus on protozoan infections, especially on giardia and coccidia.

Its is the responsibility of the society to provide adequate care to animals that had been relinquished or abandoned, and parasitological measures are an integral part of this care.

\section{Parazitární infekce v útulku pro zvířata}

Sledovali jsme možnosti omezení šíření parazitárních infekcí v útulku pro psy a kočky. U umístěných zvířat jsme prohlíželi srst a zjištovali výskyt blech a prováděli parazitologické vyšetření trusu. $K$ ochraně proti parazitům jsme použili selamektin (Stronghold), který minimalizoval populaci blech a byl vysoce účinný proti škrkavkám. Proti prokázaným infekcím dalšími parazity (Dipylidium caninum, Taenia sp., Trichuris vulpis, Giardia lamblia) jsme použili odpovídající terapii $5 \mathrm{mg}$ praziquantelu a $50 \mathrm{mg}$ fenbendazolu/kg ž.hm. po 3 dny (Caniquantel Plus). Ochrana proti parazitům v útulcích pro zvírata vyžaduje náročnější opatření než u jednotlivě chovaných psů a koček.

\section{References}

DUBEY, JP 1993: Isospora infections in dogs and cats. In: Kreier JP: Parasitic Protozoa, Volume 6, Academic Press, INC., pp. 120-125

KASSAI, T 1999: Veterinary Helmintology, Butterworth-Heinemann, p 68

McTIER, TL, JERNIGAN, AD, ROWAN, TG, HOLBERT, MS, SMOTHERS, CD, BISHOP, BF, EVANS, NA, GRATION, KAF, GILES, CJ 2000a: Dose selection of selamectin for efficacy against adult fleas (Ctenocephalides felis felis) on dogs and cats. Vet Parasitol 91: 177-185

McTIER, TL, SIEDEK, EM, CLEMENCE, RG, WREN, JA, BOWMAN, DD, HELLMAN, K., HOLBERT, MS, MURPHY, MG, YOUNG, DR, CRUTHERS, LR, SMITH, DG, SHANKS, DJ, ROWAN, TG, JENIGAN, AD 2000b: Efficacy of selamectin against experimentally induced and naturally acquired ascarid (Toxocara canis and Toxascaris leonina) infections in dogs. Vet Parasitol 91: 333-345

McTIER, TL, SHANKS, DJ, WREN, JA, SIX, RH, BROWMAN, DD, McCALL, JW, PENGO, G, GENCHI, C, SMOTHERS, CD, ROWAN, TG, JENIGAN, AD 2000c: Efficacy of selamectin against experimentally and naturally acquired infections of Toxocara cati and Ancylostoma tubaeformae in cats. Vet Parasitol 91: 311-319

MONIS, PT, ANDREWS, RH, MAYRHOFER, G, MACKRILL, J, KULDA, J, ISAAC-RENTON, JL, EY, PL 1998: Novel lineates of Giardia intestinalis identified by genetic analysis of organisms isolated from dogs in Australia. Parasitol 116: 7-19

SHANKS, DJ, ROWAN, TG, JONES, RL, WATSON, P, MURPHY, MG, SMITH, DG, JERNIGAN, AD 2000 : Efficacy of selamectin in the treatment and prevention of flea (Ctenocephalides felis felis) infestations on dogs and cats housed in simulated home environments. Vet Parasitol 91: 213-222

SVOBODOVÁ, V, SVOBODA, M, KONVALINOVÁ, J 1995: Comparison of a proof of Giardia intestinalis cysts with the presence of specific antibodies in dogs and cats. Vet Med - Czech 40: 141-146

UHLÍKOVÁ, M, HÜBNER J 1999: Larval toxocarosis - clinics, the diagnosis and therapy of disease (In Czech). Rem - Klin Mikrobiol 3: 255-259

ZAJAC, AM, LA BRANCHE, TP, DONOGHUE, AR, CHU-TENGCHIAO CHU, TC 1998: Efficacy of fenbendazol in the treatment of experimental Giardia infection in dogs. Am J Vet Res 59: 1134-1136 